\title{
ISLANDS IN LAKES AND THE SEA: HOW DO THEY DIFFER?
}

\author{
ALEXEY SHIPUNOV ${ }^{1, *}$ and LIUDMILA ABRAMOVA² \\ ${ }^{1}$ Department of Biology, Minot State University, Minot, North Dakota, USA 58701 \\ 2 Moscow South-West High School (No. 1543), 26 Bakinskikh komissarov str. 3-5, RU-119571, Moscow, Russia \\ * Corresponding author: dactylorhiza@gmail.com
}

\section{ABSTRACT}

\begin{abstract}
We studied plants on several neighbouring small islands in an Arctic lake and the sea and despite a common source of colonizers and similar environmental characteristics there were striking differences in the compositions of their floras. The best explanation of the differences could be a combination of several factors, most likely salinity and tides.
\end{abstract}

Keywords: lake islands, islands in the sea, flora, island biogeography, White Sea

\section{Introduction}

Islands are excellent models for studying different aspects of plant ecology, diversity and evolution. However, the majority of the publications on "plant island biogeography" are on a few relatively large and mostly tropical islands. There are few studies of smaller islands, regardless of the fact that these islands are often part of an archipelago, where the number of islands is sufficient to be able to statistically test the significance of the results. Small Arctic or Antarctic islands could provide an even better model since their flora is usually poor and plants are easy to find and identify (Abramova et al. 2003).

So far, most studies of island biogeography have been on islands in the sea and islands in lakes or rivers are frequently overlooked (Nilsson and Nilsson 1978; Roden 1998; Khedr and Lovett-Doust 2000; Chepinoga et al. 2012). As far as we can determine there are no studies in the literature on several islands in the sea and lakes that occur side by side in one region.

However, such a situation occurs in Northern Karelia (European Arctic). This region is rich in islets, both in the sea and in neighbouring large lakes. We decided to study their floras in order to determine if they differ. We hypothesize that if there are differences in the floras of islands in the sea and lakes they are due to the fact that the environmental conditions on islands in freshwater and the sea differ, especially in terms of salinity and tides.

Since the only real difference between these islands is their location, either in the sea or a freshwater lake, our results indicate what change in the flora of an island will occur after desalination or salinization of the surrounding water, a situation which is unfortunately not infrequent. Also, these results could add to our general knowledge of island biogeography, especially the colonization of islands and the role of the environment.

\section{Material and Methods}

To study islands in the sea and lakes, we choose the Kandalaksha Gulf area (about $800 \mathrm{~km}^{2}$ ) nearby Chupa (Karelia, Russia). There are several relatively small islands there (in fact, most of them are "islets" since their average area is about $5000 \mathrm{~m}^{2}$ ) and they are located close to the mainland, typically within $5 \mathrm{~km}$.

On the mainland there are several big freshwater lakes. In one of them, Lake Boljshoe Pulongskoe, there are many islands (about 30 per $60 \mathrm{~km}^{2}$ ), which are remarkably similar to nearby islands in the sea. There are islands in the lake and the sea that are even located "side-by-side" with the shortest distance between the islands in the sea and the lake $9.88 \mathrm{~km}$, which is comparable to the largest distances between islands in the lake $(9.68 \mathrm{~km}) .{ }^{1}$ All these islands are covered with northern taiga if subject to breezes, or tundra-like vegetation (crowberry thickets) if subject to high wind; human pressure on these islands at the time of this study was insignificant.

It is also likely that these islands have a similar origin as most of them appeared during post-glacial uplift (Koshechkin 1979), which is still continuing at approximately $0.5 \mathrm{~cm}$ per year (Serebryanaya and Shipunov 2009). Since uplift often results in the separation of lakes from the sea and subsequent desalination (Biologicheskaja produktivnostj ..., 1975), it is likely that at least some islands in lakes were located in the sea in the past. Thus, the common history and close location of the islands studied support the idea that they were colonized by organisms from the same source.

1 More information about the islands studied may be found on the Web site of the White Sea expedition: http://ashipunov.info/belomor /english/islands.htm 
Typical method of surveying was visual recording by several research teams, which is described in detail elsewhere (Shipunov et al. 2013). Most of the surveys were made during the peak of flowering (last decade of July first decade of August). For every vascular plant species found on an island, the relative abundance was recorded (Shipunov et al. 2013). Our method proved to be relatively error-prone, with the percentage of species overlooked varying between 5 and 15\% (Volkova et al. 2007), which is similar to typical "pseudo-turnover" rates (Burg et al. 2014). All lists of island plant species were included in the database used here as the main source of data for the analysis. In addition to plant lists, the database contains "abiotic" data like area, distance to the mainland (or to the outer lake shore), to the nearest island and most abundant ecotopes (Nilsson and Nilsson 1978). Every island was placed in a group based on Breslina's (1987) classification (Shipunov et al. 2013).

In total, the database contains information for 154 islands of which 118 are in the sea. To increase the comparability of the islands studied, we selected only those islands in the sea with distances from the mainland and sizes similar to the islands in the lake. As a result, very small (less than $200 \mathrm{~m}^{2}$ ) and especially large (more than $15,000 \mathrm{~m}^{2}$ ) islands in the sea were not included in the analysis. We also excluded all rocky islands in the sea belonging to the "kamen", "baklysh" and "korga" groups (terminology of Breslina 1987, see also Shipunov et al. 2013). The data used in the analysis was for 35 islands in the sea and 36 islands in the lake. All the statistical calculations were carried out using $\mathrm{R}$ environment ( $\mathrm{R}$ Core Team 2014).

\section{Results}

\section{Islands in the lake and the sea}

The total flora of these islands comprises 232 species. Islands in the lake and sea have similar numbers of species (158 and 149, respectively) but on average, the flora of islands in the lake is poorer (37 vs. 50). The unique flora of the islands in the lake comprises 91 species $(57.6 \%$ of the flora of islands in the lake), sea islands -74 species (49.7\% of the flora of islands in the sea). The most frequent (both in terms of local abundance and total presence on islands) unique species were the littoral Festuca rubra, Leymus arenarius, Sonchus arvensis on the islands in the sea and Ranunculus reptans, Juncus filiformis, Alnus incana on the islands in the lake. The number of species common to both types of islands was 67 , which is $28.8 \%$ of the total flora. The most frequent among these were the dwarf shrubs Empetrum hermaphroditum, Vaccinium vitis-idaea and Vaccinium uliginosum.

The most frequent ecotopes on the two types of island also differ. On the islands in the sea, seaside meadows, crowberry thickets and sand beaches dominated, whereas on the islands in the lake the most frequent were for- ests, rocky beaches ("boulders") and "seaside" (lakeside) rocks.

The difference between islands was assessed using principal component analysis of species abundance (Fig. 1). The first two principal components accounted for $44.3 \%$ of the variation. Separation of the islands was almost perfect with no islands in intermediate positions. Analysis of (dis)similarity between clusters revealed high and significant values: ANOSIM $R=0.98$, significance $=0.01$ ). Similar results (complete separation of subgroups) were obtained using non-metric multidimensional scaling based on occurrence data and Jaccard similarity (not shown).

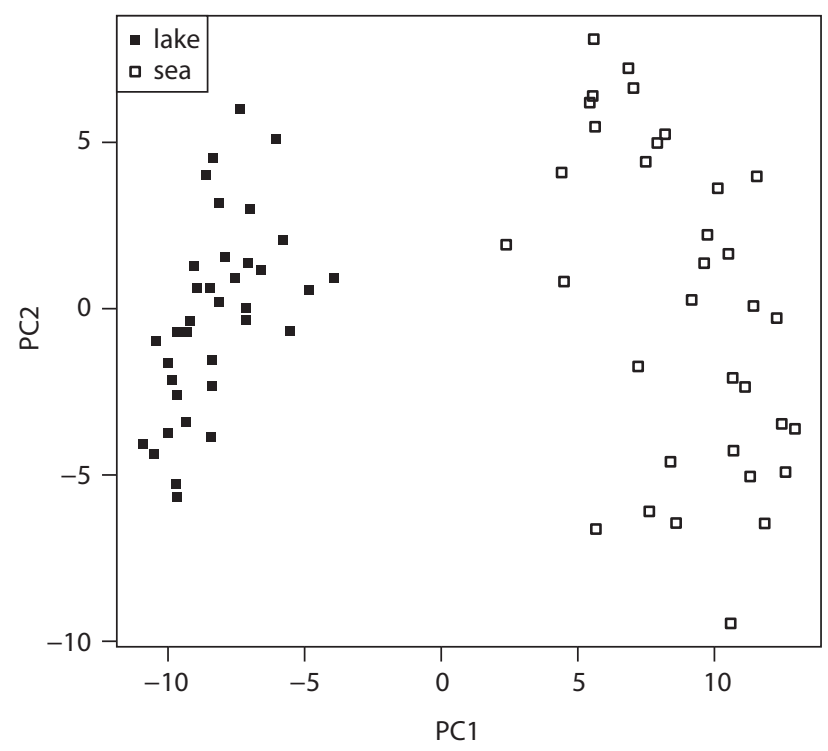

Fig. 1 Plot of a principal component analysis of the floras of islands in the sea and a lake based on species abundances.

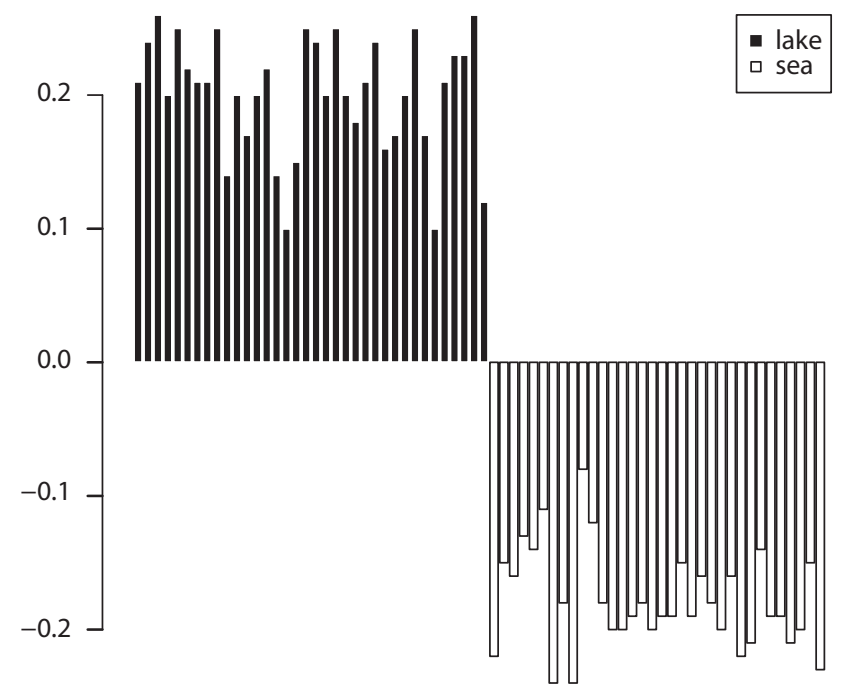

Fig. 2 Barplots of cluster memberships (result of fuzzy clustering) of all island floras in the islands in the lake cluster (the axis indicates membership values). 
Fuzzy clustering allows the determination of the membership for a given number of clusters (lake and sea in this case). We applied fuzzy clustering to our dataset. Only small deviations in membership values within each cluster (Wilcoxon test, $p<10^{-12}$ ) were recorded (Fig. 2). Again, no island in the sea or lake occurred in a "foreign" cluster.

\section{Indicator species and habitats}

Since the separation between subgroups was clear, we decided to check this separation using the diagnostic indicator (Khedr and Lovett-Doust 2000) species. First, the algorithmic analysis of species occurrence (Abramova et al. 2003) was used. The average occurrence of a given species on the islands in a particular group was divided by its average. The top 10 highest values were for Ranunculus reptans, Alnus incana, Ledum palustre, Salix phylicifolia, Juncus filiformis, Carex rostrata, Pyrola minor, Equisetum fluviatile, Salix caprea and Salix lapponum for the islands in the lake and Leymus arenarius, Festuca rubra, Sonchus arvensis, Rumex pseudonatronatus, Ligusticum scoticum, Heracleum sibiricum, Puccinellia spp., Atriplex nudicaulis, Plantago maritima and Conioselinum tataricum for the islands in the sea. Similar species lists were obtained using factor loadings of the PCA. Multidimensional scaling and canonical correspondence ordinations take into account less frequent species so the lists of indicator species obtained using these methods are slightly different. The species that separate clouds in both ordinations are Sparganium hyperboreum, Menyanthes trifoliata and Carex globularis for the islands in the lake and Triglochin palustris and Plantago media for the islands in the sea.

Canonical correspondence analysis (CCA) provided information about habitats, which was very important for

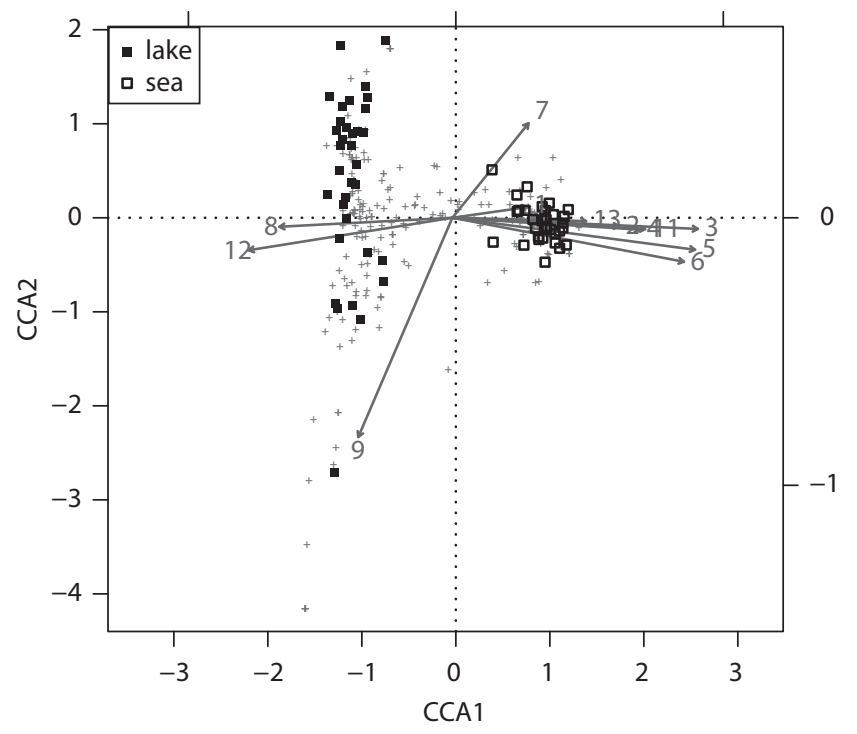

Fig. 3 Canonical correlation analysis biplot showing islands, species (grey crosses) and habitat factors (grey arrows). Habitat factors: 1 Area, 2 Distance to mainland, 3 Sandy beach, 4 Pebble beach, 5 Driftwood, 6 Seaside (lakeside) meadow, 7 Seaside (lakeside) rocks, 8 Boulders (rocky beach), 9 Swamps, 10 Pools, 11 Crowberry thickets, 12 Forest. the ordination (Fig. 3). The most influential were forests and boulders for the islands in the lake and driftwood, sandy beaches and seaside meadows for the islands in the sea.

\section{Discussion}

The size of the floras of the islands in the sea and the lake were similar, despite significant differences in the frequencies of ecotopes. Since the size of islands in the post-glacial uplift area directly corresponds with their age (Serebryanaya and Shipunov 2009) and the size of flora of an island is age-dependent (Roden 1998), this is probably a consequence of our selection rules.

We found striking differences between the floras of islands in the sea and a lake. Using indicator species we can check our preliminary hypotheses. First, we hypothesized that salinity would select for tolerant species like littoral halophytes on islands in the sea (Khedr and Lovett-Doust 2000). In fact, all the indicator species on islands in the sea are salt-tolerant (Ellenberg and Leuschner 1996; Hill et al. 1999) and some of them (like Puccinellia spp., Atriplex nudicaulis, Plantago maritima) are common plants on salty soils (Ramenskaya and Andreeva 1982). In contrast, many of the indicator species on the islands in the lake (for example, Ledum palustre, Carex rostrata, Pyrola minor) are plants of oligotrophic bogs and salt-intolerant (Ellenberg and Leuschner 1996).

The second main difference between the two types of island could be tides, which are high in the White Sea and therefore a significant factor affecting the flora of islands in the sea (Kuznetsov 1960; Breslina 1987). Most trees cannot tolerate constant and frequent flooding (Kozlowski 1997). Consistently, four of the lake indicator species are trees or large shrubs, whereas there are no woody species of plants among the indicator species in the floras of islands in the sea. This also accounts for the domination of forest ecotopes on the islands in the lake.

Other factors like sea birds (Breslina 1987; Chepinoga et al. 2012), wind and human pressure could also be important. Wind is an important factor in the development of tundra on islands (Breslina 1987), whereas the local winds blowing across lakes are less strong because they are much smaller than seas. This is in accordance with the fact that the indicator species on the islands in the lake are generally taller than those on the islands in the sea (Ramenskaya and Andreeva 1982). The role of sea birds in determining the uniqueness of the floras of the islands in the sea is supported by the fact that some of their indicator species (like Atriplex nudicaulis) are known as bird-dependent ("ornithophilous": Breslina 1987). Finally, the presence of ruderal (in this region) Plantago media among the indicator species of islands in the sea could be a sign of a still weak, but growing recreation pressure (Chepinoga et al. 2012; Shipunov et al. 2013). These last factors (birds, winds and recreation) could also explain 
the greater average size of the floras of the islands in the sea.

We conclude that, the differences in the sea and lake island reflect the dominant role of environmental factors in determining the composition of plant communities on Arctic islands.

\section{Acknowledgements}

Authors thank the participants and heads of White Sea Expedition of Moscow South-West High School for their invaluable help and support.

\section{REFERENCES}

Abramova LA, Rimskaya-Korsakova NN, Shipunov AB (2003) The comparative study of the flora of Kiv Gulf, Chupa Gulf and Keretj Archipelago islands (Kandalaksha Bay of White Sea). Proceedings of the Pertsov White Sea Biological Station 9: 22-33. (in Russian)

Winberg GG (ed) (1975) Biologicheskaja produktivnostj severnykh ozer. Ozera Krivoe I Krugloe (1975) Nauka, Leningrad. (in Russian)

Breslina IP (1987) Plants and water birds of marine islands of Kola Subarctic. Nauka, Leningrad. (in Russian)

Burg S, Rixen C, Stöckli V, Wipf S (2014) Observation bias and its causes in botanical surveys on high-alpine summits. J Veg Sci. doi: $10.1111 /$ jvs.12211.

Chepinoga VV, Zverev VE, Zvereva EL, Kozlov MV (2012) Vascular plants on the islands and peninsulas of Maloe More (Lake Baikal): patterns of diversity and species turnover. Boreal Env Res 17: 219-236.

Ellenberg H, Leuschner C (1996) Vegetation Mitteleuropas mit den Alpen. 1095. Ulmer, Stuttgart.
Hill MO, Mountford JO, Roy DB, Bunce RGH (1999) Ellenberg's indicator values for British plants. ECOFACT Volume 2 Technical Annex. Institute of Terrestrial Ecology, Huntingdon.

Khedr A-H, Lovett-Doust J (2000) Determinants of floristic diversity and vegetation composition on the islands of Lake Burollos, Egypt. Appl Veg Sci 3: 147-156.

Koshechkin BI (1979) Holocene tectonic of the eastern part of Baltic shield. Nauka, Leningrad. (in Russian)

Kozlowski TT (1997) Responses of woody plants to flooding and salinity. Tree Physiology Monograph. 1-29.

Kuznetsov VV (1960) The White Sea and biological peculiarities of its flora and fauna. AN SSSR Publisher, Moscow, Leningrad. (in Russian)

Nilsson SJ, Nilsson IN (1978) Species richness and dispersal of vascular plants to islands in Lake Möckeln, Southern Sweden. Ecology 59: 473-480.

R Core Team (2014) R: a language and environment for statistical computing. R Foundation for Statistical Computing, Vienna, Austria. http://www.R-project.org. Accessed 1 September 2014.

Ramenskaja ML, Andreeva VN (1982) Manual of the higher plants of Murmansk region and Karelia. Nauka, Leningrad. (in Russian)

Roden C (1998) Persistence, extinction and different species pools within the flora of lake islands in western Ireland. J Biogeogr 25: 301-310.

Serebryanaya A, Shipunov A (2009) Morphological variation of plants on the uprising islands of northern Russia. Ann Bot Fenn 46: 81-89.

Shipunov A, Volkova P, Abramova L, Borisova P (2013) Lost and found: short-term dynamics of the flora on 100 small islands in the White Sea. Acta Oecol 52: 50-56.

Volkova PA, Altshuler EP, Shipunov AB (2007) Complete flora of islands and lakes as a statistical hypothesis. The materials of the White Sea Expedition of Moscow South-West High School, 7. http://ashipunov.info/belomor/english/2007/noise.htm. Accessed 1 September 2014. 